\title{
Central Post Stroke Pain: The Clinical-Anatomical Correlations from Pain Clinic Stories
}

\author{
Arūnas Ščiupokas*1,2,3, Eglẻ Sukockienė ${ }^{1}$ and Gintarẻ Žemgulytė ${ }^{1}$ \\ ${ }^{1}$ Department of Neurology, Lithuanian University of Health Sciences
}

${ }^{2}$ Pain Clinic, Lithuanian University of Health Sciences Hospital Kauno Klinikos

${ }^{3}$ Locum Consultant Neurologist, National Health Service, UK

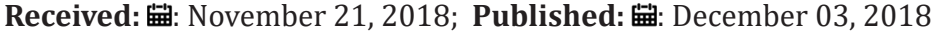

*Corresponding author: Dr Arunas Sciupokas, Department of Neurology, LUHS, Mickeviciaus 9, Kaunas LT-44307, Lithuania

\begin{abstract}
Unless a significant proportion of post stroke patients are not treated adequately, the sensory phenotype based management is proposed in the article. We evaluated three case stories of cerebral infarcts resulted to thalamic pain syndromes. The somatosensory examination each of them has found different sensory signs of thermalgesic and deep sensation, depending on where lesion occurred. In case of extra-thalamic cause of CPSP (patient 3) pain was associated with dissociated thermalgesic sensory loss due to preserved lemniscal function. Classic thalamic pain (patient 2) was accompanied by non-dissociated sensory symptoms, and the damage of the spinothalamic and dorsal column-medial lemniscal pathways altogether (patient 1) has showed loss of all sensory modalities. The study confirms that examination of sensory function is essential for diagnosis of central neuropathic pain. We think that a proper pain evaluation and long-term follow-up of stroke survivors is necessary for successful management of CPSP.
\end{abstract}

Keywords: Central Post-Stroke Pain; Clinical-Anatomical Approach; Sensory Phenotype Based Management

Abbreviations: CPSP: Central Post Stroke Pain, NRS: Numeric Rating Scale, HADS: Hospital Anxiety and Depression, MRI: Magnetic Resonance Imaging, HAD: Hospital Anxiety and Depression, LPQ: Lithuanian Pain Questionnaire, PICA: Posterior Inferior Cerebellar Artery, NRS: Numeric Rate Scale

\section{Background}

Central post stroke pain (CPSP) is a severe condition, affecting patients' lives, well-being and compromising ability to function and maintain social connections. Unfortunately, this disorder usually remains unrecognized resulting in an inadequate management and persistence of vicious pain mechanisms. Traditionally, CPSP is resulting because of ischemic or hemorrhagic stroke and corresponding to the brain territory that has been injured [1]. According to the International Association for the Study of Pain, this disease is characterized as a central neuropathic pain condition in which pain arises as a direct result of a cerebrovascular lesion in the central somatosensory nervous system. Prevalence of CPSP is estimated between $3-10.5 \%$ [2-5], however, it is widely accepted that this phenomenon is under-reported [6]. Furthermore, the pure CPSP syndrome is not common and other nociceptive stimuli and residual post-ischemic deficits blur the clinical picture of CPSP. Presence of pain itself and pain intensity result in significant decline of life quality [7-9], cognitive and functional performances
[10]. This neuropathic pain syndrome is characterized by constant or intermittent pain occurring after stroke and usually associated with the sensory abnormalities in the painful body part [2]. It is known that CPSP is associated with depression [5] and higher suicidality [11].

Only in a small portion of patients CPSP reduces over time, the vast majority of post stroke patients experience chronic, often life-long and constant pain [1]. Moreover, the diagnosis of this pain syndrome is still challenging, because the onset of pain is often delayed for one or more months after cerebrovascular accident $[12,13]$, compromising specific clinical approach and initiation of targeted treatment. Unfortunately, a significant proportion of post stroke patients are not treated adequately or are not treated at all [14]. Structural abnormalities associated with stroke in any topographical site of central somatosensory spinothalamic pathway can produce CPSP syndrome. However, lesions of thalamus, operculum-insular region or brainstem are the most 
likely to result in central neuropathic pain, each producing distinct neuropathic pain phenotype that could be recognized through the clinical examination of somatosensory system [15-17]. We aimed to illustrate this clinical problem with the case series of CPSP each representing specific lesion of central pathway and illustrating different pain sensory phenotypes which can be assessed with a simple bedside tool. These cases include somatosensory landmarks that are linked to the topography of the cerebrovascular lesions and therefore are leading to the suitable clinical evaluation and management of CPSP (Figure 1).

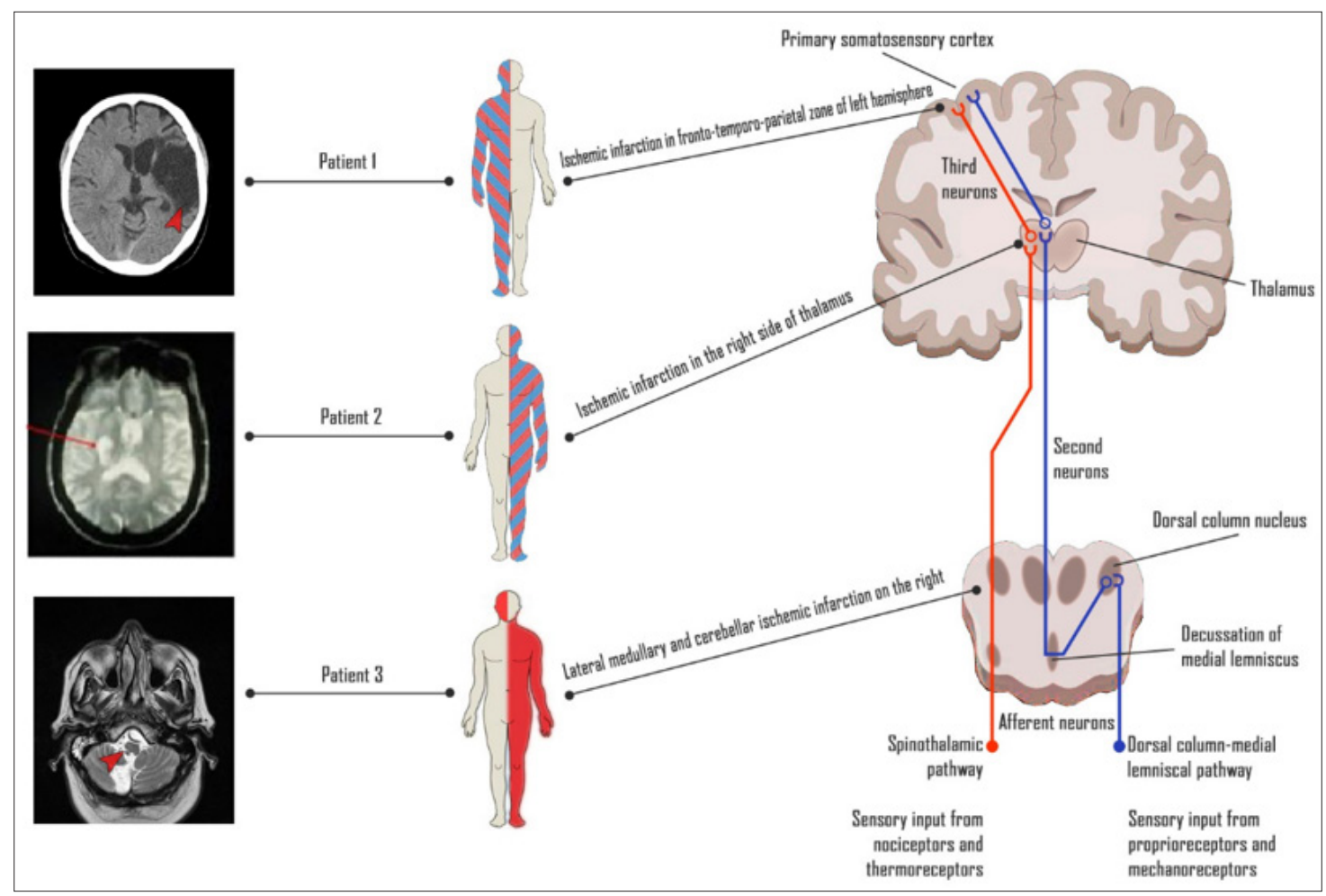

Figure 1: Clinical-anatomical correlations of central post-stroke pain.

\section{Patient 1, Hemispheric Cortical-Subcortical Lesion}

A 62-year old woman was referred by the family doctor to the pain clinic because of the pharmacologically resistant pain in her right arm and leg. The patient suffered a large cardioembolic ischemic stroke within territory of the left middle cerebral artery seven years ago. The ischemic lesion manifested with the right sided hemiplegia and global aphasia. Since the speech was severely impaired in the acute phase, sensory deficits were not determined precisely. The patient was subsequently referred to the rehabilitation facility and the neurological deficits including hemiparesis and aphasia partially resolved. However, after 12 months, the burning feeling in the right side of face and body appeared, and these symptoms worsened at night. To relieve the pain, the patient used NSAIDs and tramadol, however without success. The examination in the pain clinic has showed severe burning pain of $8 / 10$ intensity by Numeric rating scale (NRS). The patient also was complaining of the weakness and spasticity in her right extremities with ability to walk only with a stick or unilateral assistance. The unpleasant feeling of numbness both itching, and emotional distress with anxiety, poor sleep were main related symptoms worsening during physical activity.
Neurological examination revealed severe motor aphasia with right spastic hemiparesis both significant somatosensory signs including complete loss of temperature sensation, reduced vibration and joint position senses in the right hemi-body. In addition, mechanical allodynia and pin-prick hyperalgesia phenomena were positive in the affected side mainly in the face and upper extremity. Deep tendon reflexes were increased with Babinski sign on the right side. The patient filled in the Hospital anxiety and depression (HADS) scale, and the scores for each subscale revealed a clinically significant levels of anxiety (A-11) and no markedly evident signs of depression (D-3). The patient scored 7 points in DN4 (Douleur Neuropathique en 4 Questions) questionnaire which showed $83 \%$ sensitivity and $90 \%$ specificity of neuropathic pain. The plan of pain management was developed by the pain physician and included 5 days course of intravenous ketamine injections, constant intake of amitriptyline $50 \mathrm{mg} / \mathrm{d}$ and as for spasticity three weeks course of Tolperizone $300 \mathrm{mg} / \mathrm{d}$. The Tramadol was gradually discontinued due to the lack of effectiveness. At followup visit after one month, the patient reported a marked relief of CPSP symptoms. The intensity of the pain was estimated in $3 / 10$ by NRS. Since amitriptyline was effective and the tolerance was good, 
the patient was advised to increase the dosage to $62.5 \mathrm{mg} / \mathrm{d}$ and continue for next 2 months.

\section{Patient 2, Thalamic Lesion}

A 62-year-old man was referred by the family doctor to the Pain clinic, because the patient experienced intense burning pain with the feeling of numbness in his left side of the body. Seven years ago he suffered an ischemic stroke of cardio-embolic origin within territory of the right posterior cerebral artery. The Magnetic Resonance Imaging (MRI) has confirmed the ischemic lesion in the right side of thalamus in about $15 \mathrm{~mm}$ in diameter. His initial neurological symptoms included left hemiparesis, hemi-hypoesthesia and a mild disturbance of coordination on the left side. The patient has fulfilled 10 days of treatment in Neurology department, then completed recovering process at the rehabilitation facility. The weakness of his left side of the body has gradually resolved. However, numbness of his left hemi-body turned into a painful feeling. The central neuropathic pain was initially treated conservatively with pregabalin and baclofen. However, these medications were not effective and the patient still experienced intense pain that disturbed his physical and social functioning. After a few years of unsuccessful conservative treatment, the patient was consulted by a neurosurgeon, and the stereotactic mesencephalotomy of the right side was performed. Unfortunately, the pain still remained, furthermore, involuntary dystonic movements of his left extremities have occurred. Subsequently, almost all groups of potential analgesics or neuropathic pain relievers were tried.

The patient did not report any significant effect from any of these substances and the pain remained. The examination in the pain clinic has reported severe burning pain (8/10). The patient also experienced involuntary movements in his left arm and the gait disturbance with signs of clumsiness on the left. The pain was not constant, it was associated with the movements, and met with the periods of exacerbations lasted from two to three weeks. In addition, dystonic movements of his left hand and dystonic, clumsy gait were evident on clinical examination. Complete sensory loss, including loss of temperature, pain and touch sensations was found on somatosensory examination. Deep tendon reflexes were asymmetric, and extensor plantar response was found on the left side. The patient filled in the HAD (Hospital Anxiety and Depression) scale, and the scores for each subscale revealed a mild level of anxiety and depression (A - 8, D -10). Pain quality was tested by of Lithuanian pain questionnaire (LPQ) which is analogue of MPQ (McGill Pain Questionnaire), and revealed a moderate sensory (5.5) and affective (4) components of pain. The patient scored 5 points in DN4 questionnaire, what showed only suspicious for a diagnosis of neuropathic pain. The final diagnosis was formulated as sensory disturbance in the left side of the body, central neuropathic pain, and state after ischemic cerebrovascular event. The possibility of deep brain stimulation was considered with the neurosurgeon; however, it was not performed due to lack of evidence of this treatment method be effective now. Further recommendations consisted of pharmacological pain management with gabapentin $900 \mathrm{mg} / \mathrm{d}$ combined with clonazepam $2 \mathrm{mg}$ at night. Follow up in three months has showed no significant change in patient's status.

\section{Patient 3, Brainstem Lesion}

A 68-year-old woman was referred by neurologist to the Pain clinic because of severe headache. Five months ago an ischemic stroke was diagnosed. She had a sudden onset of dysarthria, coordination disturbance with ataxic gait and left hemi-syndrome. Consequently, residual lesions in the right inferior medial cerebellar hemisphere, corresponding to the right PICA (posterior inferior cerebellar artery) blood supply zone were confirmed with the MRI scan, and thrombosis of the right vertebral artery was found. A few days after the initial stroke symptoms she started to feel burning pain with the shooting character in her right side of the face. Sharp painful feeling was constant and exacerbated at night. The patient was using pregabalin $300 \mathrm{mg} / \mathrm{d}$ and ibuprofen $1200 \mathrm{mg} / \mathrm{d}$ with partial effect. At the pain clinic patient's pain was mild at $4 / 10$ by numeric rate scale (NRS). However, she has had the exacerbations like breakthrough pains rated at 9-10/10.

The somatosensory examination has revealed sensory loss of temperature and pain in her right side of face (ipsilateral) and left part of body (contralateral), and deep tendon reflexes were slightly higher on the left with no motor deficit. Coordination on the left was impaired, and her gait was ataxic. All these clinical findings indicated lesion of central nervous system including somatosensory pathway at the level brainstem and cerebellar dysfunction. The patient was advised to use carbamazepine 400 $\mathrm{mg} / \mathrm{d}$, amitriptyline $20 \mathrm{mg} / \mathrm{d}$ and ibuprofen $400 \mathrm{mg}$ for pain exacerbations. Follow-up visit in two months has showed the pharmacological pain management still was not sufficient and the pain on the face became more intensive and with added rhinorrhea. She reported moderate pain with intensity 6/10. Because of new clinical presentation the brain MRI scan was repeated and revealed residual post - ischemic changes in the right posterior circulation territory that were mentioned before, and acute mastoiditis on the same side. The cause of new type of pain was confirmed and the patient was referred to otorhinolaryngologist and the specific treatment for this pathology was prescribed.

\section{Discussion}

The exact pathophysiology of CPSP is still not well understood, however, major known aspects of CPSP pathophysiology include deafferentation, disinhibition and abnormal spinothalamic function mechanisms, [18-20] resulting in a wide spectrum of sensory abnormalities and neuropathic pain. The first step in assessing the CPSP is differential diagnosis between nociceptive and neuropathic pain. Clinical properties of CPSP include continuous or evoked schemes with raised thresholds to thermal pain, abnormal sensibility to pin-prick, hyperpathia, dysaesthesia, paraesthesias, radiation of stimuli, after-sensations, allodynia, vibration sensibility or raised thresholds to the perception of touch $[18,21]$. The most important feature of CPSP, in addition to the pain in a stroke-affected body region, is the occurrence of negative and/or positive symptoms and signs in the same body region [22]. The most characteristic verbal pain descriptors include "aching", "burning", "squeezing", raising suspicion of the lesion in somatosensory pathway [23]. If classified according the site of origin, CPSP might be divided into 
extra-thalamic and thalamic pain. Regarding extra-thalamic causes of CPSP, it has been suggested that operculum-insular origin or, historically, "parasylvian" pain, is associated with dissociated thermalgesic sensory loss due to preserved lemniscal function [17].

It is clinically similar to CPSP as a symptom due to lateral medullary lesions [24], illustrated by the case of Patient 3. The sensory phenotype of this patients was produced by the lateral medullary lesion, affecting spinothalamic tract and sensory nucleus of trigeminal nerve. Importantly, the latter case is an illustration of the fact that CPSP is associated with only a partial damage of somatosensory system, since the acute disease (in this case, mastoiditis) resulted in the new nociceptive impulses that overlapped with the symptoms of the CPSP and worsened the chronic pain. For this reason, the clinical alertness and individual approach to each patient is crucial. In contrast to the lateral medullary lesions, classic thalamic pain is accompanied by nondissociated sensory symptoms [25], as depicted in the case of Patient 2. Meanwhile, the sensory phenotype connected to the CPSP in the case of Patient 1 involves loss of all sensory modalities in the affected body part due to the damage of the spinothalamic and dorsal column-medial lemniscal pathways altogether.

However, pure CPSP sensory syndromes are not common, often lacking characteristic components or mixing with neuropathic and nociceptive pain conditions from other anatomical sources [24]. To facilitate differential diagnosis, the grading system for CPSP had been developed. It consists of these criteria: exclusion of other likely causes of pain, pain with a distinct neuro-anatomically plausible distribution, confirmed with neurological evaluation, a history of stroke and demonstrating of the relevant vascular lesion by imaging [26]. Assessment of neuropathic pain including CPSP involves a series of systematic steps, including medical history of the pain (pain location, distribution, intensity, quality and time course, separation into stimulus-independent and stimulusdependent pain), clinical sensory examination (negative sensory symptoms and findings as well as static or dynamic positive sensory symptoms which are tested with pinprick, touch, pressure, cold, heat and vibration tests) and pharmacological testing (using a double-blind placebo controlled technique with either different drugs or different administration forms of the same substance) [27]. Examination of sensory function is essential for diagnosis of central neuropathic pain. It can be performed in a bedside manner with simple tools, such as cotton wool for touch, a sharp stimulus for pain, a metal thermal roller for temperature sensation and soft brush for dynamic allodynia [28]. As in our described cases, different standardized tools, for example, LPQ (analogue of McGill Pain Questionnaire), DN4, pain drawings also give an additional important information and are useful in the follow-up and evaluation of treatment effect. Treatment of CPSP is a constant challenge and it often involves trial-and-error process with multiple different therapies [6]. The effects of certain groups of pharmacological agents, for example, tricyclic antidepressants, anticonvulsants are well established in a wide range of neuropathic pain conditions [29]. Efficacy of amitriptyline and lamotrigine on CPSP are proven in randomized controlled trials [30]. On the basis of evidence and clinical experience, amitriptyline is considered the drug of first choice [12]. On the other hand, the utility of amitriptyline is limited by its well-known and sometimes serious side-effects, including sedation, urinary retention, orthostatic hypotension and cardiac arrhythmia [12]. Antidepressants with a better side-effect profile (i.e. serotonin-specific re-uptake inhibitor category) appear to be less effective in CPSP, but there are no published clinical studies that confirm this lack of benefit [22].

Pregabalin and gabapentin are also proved to provide sustained efficacy in different chronic central neuropathic pain conditions and to have good tolerability [31,32]. In contrast, data from several double-blinded placebo-controlled trials suggest, that carbamazepine [33], levetiracetam [34] and duloxetine [35] have not enough effect on CPSP. Opioid analgesics should be considered as a second line or an add-on therapy for neuropathic pain, for example, gabapentin plus tramadol [36, 37]. Neuro-stimulation therapy, such as motor cortex stimulation, deep brain stimulation, and transcranial magnetic stimulation, is used for treatmentresistant cases of CPSP, however, there is not enough data about the efficacy of these treatment methods [26]. Our cases illustrate the fact that the most successful therapies usually are the ones who target the increased neuronal hyper-excitability [26].

We believe that the distinct somatosensory phenotype of each CPSP case is one of factors of varying treatment response from case to case. In addition to recognition of CPSP itself, the determination of the specific phenotype should be included in the process of the choice of treatment modality, however, further studies are needed to establish certain recommendations. [38] Moreover, a variable the time gap exit between the onset of stroke and first symptoms of the central pain. This phenomenon is related to certain structural changes in the central nervous system $[39,40]$. Subsequently, we hypothesize that certain targeted interventions may serve as a prophylaxis reducing the risk of developing or severity of CPSP, for example, inhibition of microglial activation or inflammatory response [41]. However, the further exploration of these ideas is needed. As a result, every patient who suffered from cerebrovascular accident should be appointed for the follow-up visits in primary care units to screen for CPSP and to avoid potentially irreversible secondary changes in somatosensory system leading to chronic pain syndrome and additional burden to the physical disability together with drug-induced side effects, sequel of inadequate surgery and socio-economic impact.

\section{Conclusion}

CPSP is common in post-stroke population, but it usually remains unidentified. It is important to raise awareness about this condition in primary care physicians to ensure timely diagnosis. Our reported cases reflect the clinical-anatomical approach to the CPSP characteristics in each individual case. They also illustrate difficulties and obstacles that patients and physicians struggle managing this syndrome. Unfortunately, patients deal not only with pain, but also with multiple side effects of polypharmacy 
together with complications of repetitive interventions. To sum up, successful management of this debilitating complication requires not only pathophysiological understanding and timely recognition of CPSP, but also proper pain evaluation and long-term follow-up of stroke survivors.

\section{References}

1. Klit H, Finnerup NB, Jensen TS (2009) Central post-stroke pain: clinical characteristics, pathophysiology, and management. Lancet Neurol 8(9): 857-868.

2. Andersen G1, Vestergaard K, Ingeman Nielsen M, Jensen TS (1995) Incidence of central post-stroke pain. Pain 61(2): 187-193.

3. Hansen AP, Marcussen NS, Klit H, Andersen G, Finnerup NB, et al. (2012) Pain following stroke: A prospective study. Eur J Pain Eur J Pain 16(8): 1128-1136.

4. Harno H, Haapaniemi E, Putaala J, Haanpää M, Makela JP, et al. (2014) Central poststroke pain in young ischemic stroke survivors in the Helsinki Young Stroke Registry. Neurology 83(13): 1147-1154.

5. Lundstrom E, Smits A, Terent A, Borg J (2009) Risk factors for strokerelated pain 1 year after first-ever stroke. Eur J Neurol 16(2): 188-193.

6. Harrison RA, Field TS (2015) Post stroke pain: Identification, assessment, and therapy. Cerebrovascular Diseases 39(3-4): 190-201.

7. Tang WK, Lau CG, Mok V, Ungvari GS, Wong KS (2015) The impact of pain on health-related quality of life 3 months after stroke. Top Stroke Rehabil. 22(3): 194-200.

8. Jonsson AC, Lindgren I, Hallstrom B, Norrving B, Lindgren A (2006) Prevalence and intensity of pain after stroke: a population based study focusing on patients' perspectives. J Neurol Neurosurg Psychiatry 77: 590-595.

9. Şahin Onat Ş, Ünsal Delialioğlu S, Kulaklı F, Özel S (2016) The effects of central post-stroke pain on quality of life and depression in patients with stroke. J Phys Ther Sci 28(1): 96-101.

10. Donnell MJ, Diener HC, Sacco RL, Panju AA, Vinisko R, et al. (2013) Chronic pain syndromes after ischemic stroke: PRoFESS trial Stroke 44(5): 1238-1243.

11. Tang WK, Liang H, Mok V, Ungvari GS, Wong KS (2006) Is pain associated with suicidality in stroke? J Neurol Neurosurg Psychiatry 77(5): 590595.

12. Hansson P (2004) Post-stroke pain case study: clinical characteristics, therapeutic options and long-term follow-up. Eur J Neurol 1: 22-30.

13. Paolucci S, Iosa M, Toni D, Barbanti P, Bovi P, et al. (2015) Neuropathic pain special interest group of the Italian Neurological Society. Prevalence and Time Course of Post-Stroke Pain: A Multicenter Prospective Hospital-Based Study. Pain Med pii: pnv019.

14. Widar M, Samuelsson L, Karlsson Tivenius S, Ahlström G (1989) Longterm pain conditions after a stroke. Pain 36(1): 13-25.

15. Leijon G, Boivie J, Johansson I (1989) Central post-stroke pain-neurological symptoms and pain characteristics. Pain 37(2): 173-185.

16. Klit H, Hansen AP, Marcussen NS, Finnerup NB, Jensen TS (2002) Early evoked pain or dysesthesia is a predictor of central poststroke pain. J Rehabil Med 34(4): 165-170.

17. Garcia Larrea L, Perchet C, Creac HC, Convers P, Peyron R, et al. (2012) Operculo-insular pain (parasylvian pain): a distinct central pain syndrome. Brain 135(8): 2536-2545.

18. Boivie, J, Leijon G, Johansson I (1989) Central post-stroke pain -a study of the mechanisms through analyses of the sensory abnormalities. Pain 37(2): 173-185.
19. Greenspan JD, Ohara S, Sarlani E, Lenz FA (1995) Allodynia in patients with post-stroke central pain (CPSP) studied by statistical quantitative sensory testing within individuals. Pain 61(2): 177-186.

20. Vestergaard K, Nielsen J, Andersen G, Ingeman Nielsen M, ArendtNielsen L, et al. (2010) Sensory abnormalities in consecutive, unselected patients with central post-stroke pain. Brain 133(9): 2528-2539.

21. Raffaeli W, Minella CE, Magnani F, Sarti D (2004) Population-based study of central post-stroke pain in Rimini district, Italy. Pain 109(3): 357-366.

22. Bowsher D (1999) Central post-stroke ('thalamic syndrome') and other central pains. Am J Hosp Palliat Care 16(4): 593-597.

23. Harrison RA, Field TS (2012) Post stroke pain: identification, assessment, and therapy. Eur J Pain 16(8): 1128-1136.

24. Kim JS, Lee JH, Lee MC (2015) Patterns of sensory dysfunction in lateral medullary infarction. Clinical-MRI correlation. Pain 156(11): 23372353.

25. Sprenger T, Seifert CL, Valet M, Andreou AP, Foerschler A, et al. (1997) Assessing the risk of central post-stroke pain of thalamic origin by lesion mapping. Neurology 49(6): 1557-1563.

26. Klit H, Finnerup NB, Jensen TS (2009) Central post-stroke pain: clinical characteristics, pathophysiology, and management. Lancet Neurol 8(9): 857-868.

27. Jensen TS, Baron R (2003) Translation of symptoms and signs into mechanisms in neuropathic pain. Pain 102(1-2): 1-8.

28. Haanpää M, Attal N, Backonja M, Baron R, Bennett M, et al. (2011) NeuPSIG guidelines on neuropathic pain assessment. Pain 152(1): 1427.

29. Attal N, Cruccu G, Baron R, Haanpää M, Hansson P, et al. (2010) EFNS guidelines on the pharmacological treatment of neuropathic pain: 2010 revision. Eur J Neurol 17(9): 1113-e88.

30. Frese A, Husstedt IW, Ringelstein EB, Evers S (2006) Pharmacologic treatment of central post-stroke pain. Clin J Pain 22(3): 252-260.

31. Onouchi K, Koga H, Yokoyama K, Yoshiyama T (2014) An open-label, long-term study examining the safety and tolerability of pregabalin in Japanese patients with central neuropathic pain. J Pain Res. 7: 439-447.

32. Finnerup NB, Attal N, Haroutounian S, McNicol E, Baron R, et al. (2015) Pharmacotherapy for neuropathic pain in adults: a systematic review and meta-analysis. Lancet Neurol 14(2): 162-173.

33. Leijon G, Boivie J (1989) Central post-stroke pain - a controlled trial of amitriptyline and carbamazepine. Pain 36(1): 27-36.

34. Jungehulsing GJ, Israel H, Safar N, Taskin B, Nolte CH, et al. (2013) Levetiracetam in patients with central neuropathic post-stroke pain--a randomized, double-blind, placebo-controlled trial. Eur J Neurol 20(2): 331-337.

35. Vranken JH, Hollmann MW, van der Vegt MH, Kruis MR, Heesen M, et al. (2011) Duloxetine in patients with central neuropathic pain caused by spinal cord injury or stroke: a randomized, double-blind, placebocontrolled trial. Pain 152(2): 267-273.

36. Moulin D, Boulanger A, Clark AJ, Clarke H, Dao T, et al. (2014) Pharmacological management of chronic neuropathic pain: revised consensus statement from the Canadian Pain Society. Pain Res Manag 19(6): 328-335.

37. Chaparro LE, Wiffen PJ, Moore RA, Gilron I (2012) Combination pharmacotherapy for the treatment of neuropathic pain in adults. Cochrane Database Syst Rev 11: 7.

38. Woolf CJ, Max MB (2001) Mechanism-based pain diagnosis: issues for analgesic drug development. Anesthesiology 95(1): 241-249.

39. Roosink M, Geurts AC, Ijzerman MJ (2010) Defining post-stroke pain: diagnostic challenges. Lancet Neurol 9(4): 344. 
40. Iadecola C, Anrather J (2011) The immunology of stroke: from mechanisms to translation. Nat Med 17(7): 796-808.

\section{ISSN: 2574-1241}

DOI: $10.26717 / B J S T R .2018 .11 .002133$

Arūnas Ščiupokas. Biomed J Sci \& Tech Res

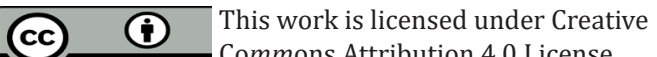

Submission Link: https://biomedres.us/submit-manuscript.php
41. Hanada T, Kurihara T, Tokudome M, Tokimura H, Arita K, et al. (2014) Development and pharmacological verification of a new mouse model of central post-stroke pain. Neurosci Res 78: 72-80.

$\begin{array}{ll}\text { BIOMEDICAL } & \text { Assets of Publishing with us } \\ \text { RESEARCHES } & \text { - Global archiving of articles } \\ & \text { - Immediate, unrestricted online access } \\ \end{array}$

